\title{
Review of Journal of Institute of Science and Technology (JIST), Vol. 18 No. 1, 2013
}

\author{
Nanda Bahadur Singh \\ Central Department of Zoology \\ Tribhuvan University, Kirtipur, Kathmandu, Nepal
}

One day morning I came across Prof. Tika Ram Aryal, who asked my favour of reviewing a Journal of "Institute of Science and Technology" (IOST) Volume 18, Number 1, January-June issue of 2013. He gave me a beautiful journal with $50 \%$ blue and $50 \%$ red coverage with TU logo as we as the logo of IOST. The contents of journal consist of altogether 25 articles including one "comment article" as well with a total of 168 pages. The quality of the printed paper of the journal is very high with its fascinating design. The journal is published by IOST, TU, Kirtipur, Kathmandu, Nepal. Dean of IOST, TU, Chirika Shova Tamrakar is acting as the advisor whereas Prof. Tika Ram Aryal is the Chief Editor along with his five members' editorial team from different departments of IOST, TU.

I went through the journal with my critical eyes of unraveling the body of knowledge system to the radiant readers! I found the IOST journal of interesting combination of tripartite confluence of mathematical sciences, physical sciences and biological sciences. Then, I tried to swim much deeper into the roots of types of authors, institutes involved and the length of the articles written. Very renowned authors of international repute have also contributed articles to this journal. Out of 25 articles written, 15 articles are of single authors, 6 articles are of double authors, 2 articles are of triple authors, 1 article is of quadruple authors and 1 article is of penta authors. Another wonderful involvement of academic institutes is also highly demonstrated in the journal. Out of 25 articles contributed, 12 articles are contributed by Central Departments of IOST, TU, 6 articles are contributed by different campuses in the valleys, 3 articles are received from out of valley campuses, 1 article is written by a combined effort of Trichandra College (TC) along with an environment related NGO, 1 article is accepted from TU along its collaboration in the US, 1 article is the product of TU along with TC and finally 1 article is an example of collaborative research of TU and the concerned ministry of government of Nepal. In this regards, the journal is a perfect representative model of many concerned stakeholders involved. If such kinds of activities are continue to occur in the days ahead, the scope and sphere of the journal will automatically be expanded and broadened to the larger number of readers with quality feed back to improve.
So far as the length of each and every article is viewed, it will be another exciting matter to know as well. Out of 25 articles published, 1 article is of 12 pages is the longest article on the dung beetles of Dhanusha district whereas 4 articles are of shortest nature with 4 pages on zoology, mathematics, and environment. Other 3 articles are of 5 pages related to education mathematics and chemistry. Next comes 5 articles with 6 pages are touched upon statistics, zoology, geology, and chemistry. Six articles are with 7 pages are on physics, chemistry, zoology and environment. Two articles with 8 pages are on Zoology and environment. Three articles with 9 pages are on chemistry, physics, and statistics. At last, but not the least, one article with 10 pages is related to the research on environmental science.

The articles such as Bayesian approach to modeling porosity of a rice variety in Nepal; probability model to describe the distribution of migrants; wind power density over Kathmandu valley and its surrounding areas; status and distribution of the great slaty woodpecker Mulleripicus pulverulentus in Chitwan national park; abinitio study of the interactions between moieties in the surfactant mediated synthesis of cobalt nanodots; removal of arsenic (V) from aqueous media using Dalbergio sissoo sawdust; evaluation of charcoal produced by biomass carrying technologies in community forests of Kathmandu valley; application of demographic models to investigate levels, differentials, and determinants of fertility of Nepal; are to name a few suggestive articles to read more conspicuously with a view to harness the knowledge benefit and a sense of innovative outcomes in the research articles. By reading those articles, one can get a diverse methods, models, approaches, and innovative ideas on different spheres of knowledge in the field of science and technology.

Besides these strengths in the journals, I also tried to dig out the other side of the same coin in terms of its weaknesses. I found only few printing mistake in the journal. In Nilam Shrestha's article heading, there should be "presence" instead of "prencence" on page 144 and in Ramesh Raj Pant's article, there should be "the' instead of "he" on the page 166 under the topic of theory courses. More than that, the continuity of the journal of IOST is more significant than anything else. I also suggest making this journal easily available in the academic market to buy for many readers. 